\title{
Background Factors Involved in the Epidemiology of Functional Constipation in the Japanese Population
}

Sayuri Yamamoto ( $\square$ yuri3337@aichi-med-u.ac.jp)

Aichi Medical University https://orcid.org/0000-0002-2729-5078

\section{Wataru Ohashi}

Aichi Medical University

Yoshiharu Yamaguchi

Aichi Medical University

Shunsuke Inamoto

Aichi Medical University

Akira Koshino

Aichi Medical University

Tomoya Sugiyama

Aichi Medical University

Kazuhiro Nagao

Aichi Medical University

Yasuhiro Tamura

Aichi Medical University

Shinya Izawa

Aichi Medical University

Masahide Ebi

Aichi Medical University

Jun Usami

Aichi Medical University

Koichi Hamano

Aichi Medical University

Junko Izumi

Aichi Medical University

Yoshinori Wakita

Aichi Medical University

Yasushi Funaki

Aichi Medical University

Naotaka Ogasawara

Aichi Medical University

Makoto Sasaki 
Aichi Medical University

\section{Masato Maekawa}

Aichi Medical University

Kunio Kasugai

Aichi Medical University

\section{Research}

Keywords: Functional constipation, Population composition ratio, Online survey, Awareness of constipation, Background factors

Posted Date: October 22nd, 2021

DOl: https://doi.org/10.21203/rs.3.rs-981969/v1

License: (c) (i) This work is licensed under a Creative Commons Attribution 4.0 International License. Read Full License 


\section{Abstract}

Background: Little is known about the prevalence and epidemiology of functional constipation (FC), a functional bowel disorder with symptoms of constipation. This study aimed to examine the prevalence, population composition, lifestyle, quality of life, and clinical characteristics of individuals with and without FC and of individuals with a strong or weak awareness of constipation.

Methods: An internet survey revealed that $262(8.7 \%)$ out of 3,000 respondents from the general Japanese population were diagnosed with FC. Moreover, all respondents were classified according to their awareness of constipation (i.e. strong or weak), and their characteristic features were compared.

Results: FC occurrence was associated with the elderly population, females, and homemakers. Its onset was associated with a change in the frequency of bowel movement, sensation of incomplete or hardly any evacuation, and the use of manual maneuvers, which are consequential clinical symptoms of FC. Subjects with FC also frequently skipped breakfast, had insufficient sleep, had more severe constipation, and had purchased laxatives in pharmacies or online more often than individuals without FC. A strong awareness of constipation was significantly more prevalent among women and homemakers. A history of anemia and cardiovascular disease was significantly more frequent in the strong awareness group, whereas a history of hypertension was more frequent in the weak awareness group.

Conclusions: Based on the understanding of the characteristic features of FC, appropriate and comprehensive management considering the patient's symptoms and lifestyle should be provided.

\section{Background}

The definition and diagnostic criteria for chronic constipation have been recently updated in the Rome IV criteria. ${ }^{1}$ According to this classification, functional constipation (FC) is diagnosed when two or more of the following six symptoms are present - "straining during at least $25 \%$ of defecations", "lumpy or hard stools (type 6 or 7 on the Bristol stool scale)", 2, 3 "sensation of incomplete evacuation," "sensation of anorectal obstruction," "manual maneuvers to facilitate defecation," and "fewer than three defecations per week" - and when both following conditions are met - "loose stools rarely present without use of laxatives" and "does not meet Rome IV criteria for irritable bowel syndrome (IBS)". These conditions must be met for the past 3 months, with symptom onset of at least 6 months prior to diagnosis. ${ }^{4}$ Japan's Clinical Guidelines for Chronic Constipation 2017 defined constipation as a "state in which feces that should be eliminated from the body cannot be passed in sufficient quantity and in comfort" and explained that it can "cause symptoms requiring examination and treatment due to reduced frequency of defecation (e.g. abdominal pain, abdominal bloating, etc.), hard stools (e.g. difficulty in defecating, excessive straining during defecation, etc.), or evacuation disorder (e.g. difficulty in defecating even loose stools, excessive straining during defecation, sensation of incomplete evacuation and therefore frequent defecation)." It has been reported to affect $1-27 \%$ of the population, with the wide range attributed to variations on the population studied, definition used, and evaluation method. ${ }^{4}$ Chronic constipation is a 
disease of high prevalence, characterized by gastrointestinal symptoms frequently encountered in different medical specialties and not only in gastroenterology. ${ }^{5} \mathrm{~A}$ study on the impact of various functional gastrointestinal disorders, including constipation, on survival reported that subjects with chronic constipation had a significantly higher risk for poorer survival than subjects with other disorders. Therefore, constipation should not be taken lightly. ${ }^{6}$ Prior to the establishment of guidelines, initial diagnoses and treatment approaches were based on the physician's individual experience. Thus, there is limited information on the prevalence and actual disease status of patients with constipation. Moreover, few patients consult with constipation as their chief complaint. Patients with constipation tend to selfmedicate using over-the-counter (OTC) medications or implement their own lifestyle modifications. 5, 7, 8, 9 This is due to the fact that constipation is not regarded as a disease, ${ }^{10}$ there is no clear definition or diagnostic criteria for chronic constipation, and an initial diagnosis and treatment approach are based on clinical experience. Although evidence-based management of constipation has recently been promoted since the publication of the Clinical Guidelines for Chronic Constipation 2017, ${ }^{4}$ only a few large-scale implementations have been reported thus far. $8,11,12$ In Japan, there are only two existing reports ${ }^{8,13}$ on the public awareness of constipation and its actual incidence, as well as the medication use and quality of life (QOL) of patients with constipation. Therefore, much remains unknown about the epidemiology of FC and its background, such as the status of constipation, medication, and treatment satisfaction. Here, we performed an online survey to determine the actual FC situation in Japan, investigating the frequency of symptoms, background factors, treatment, and QOL.

In Japanese subjects with awareness of constipation, the frequency and FC-related factors according to the Rome III criteria ${ }^{14}$ were studied in comparison with subjects with non-functional constipation (nonFC). The factors associated with a strong awareness of constipation were also studied.

\section{Methods}

\section{Subjects}

The survey was conducted on October 8-11, 2016, among 10,000 panelists aged 20-69 years from the general population who were registered with Rakuten Insight (Osaka, Japan), an internet survey company. All survey participants gave their informed consent. Valid answers were received from 9,523 subjects, and $4,908(51.5 \%)$ of these subjects responded to the question "Do you think you have constipation?" with "I strongly think I have constipation" or "I think I have constipation." Of 4,908 subjects with awareness of constipation, 3,000 were randomly extracted by fitting the general population composition ratio by prefecture, sex, and age, which was considered to reflect the demographic profile in Japan as estimated by the Statistics Bureau, Ministry of Internal Affairs and Communications of Japan as of October 1, 2014.

\section{Exclusion criteria}

The following subjects were excluded from the survey: subjects with organic diseases such as cancer and inflammatory diseases, neurological diseases, endocrine disorders, and secondary constipation 
induced by medication (e.g. opioids, antidepressants, anticholinergic agents, calcium blockers, proton pump inhibitors, etc.).

\section{Survey}

The information elicited from each study participant are as follows: age, sex, educational history, occupation, residence, history of other diseases, lifestyle, which included smoking/drinking habits using the Japanese Health Practice Index (JHPI), medication use, symptoms of constipation according to the Rome III criteria, ${ }^{14}$ stool types according to the Bristol stool scale, ${ }^{2,3}$ and use of laxatives, including the place of purchase and cost per month or acceptable cost per month. Participants also took an 8-item Short Form Health Survey Questionnaire (SF-8) ${ }^{15}$ FC was diagnosed based on Rome III criteria, ${ }^{14}$ which differed from the Rome IV criteria on the diagnosis of IBS in that chronic abdominal pain or discomfort is experienced at least 3 days per month instead of at least 1 day per week.

Of the 3,000 participants extracted, those who answered "I think so" to the question "Do you usually think that you have constipation?" were classified into the strong awareness group and the rest were classified into the weak awareness group. A comparative study was conducted for both groups.

\section{Statistical analysis}

The level of significance of the statistical analysis was set at $P<0.05$ (two-sided). The two-sided 95\% confidence interval was calculated where appropriate. To calculate the confidence interval of a proportion and the $95 \%$ confidence interval of a proportion of cases, the exact method (Clopper-Pearson) based on F-distribution was used. Unpaired $t$-tests were used to compare continuous data between the two groups. We used Fisher's exact test to compare categorical (nominal) variables and investigate whether the proportions of one variable are different from the values of another variable. In addition, we used pairwise comparisons between proportions, with Benjamini-Hochberg adjustment of the $P$ values, to further investigate which categories of the nominal variables showed significant differences. Logistic regression with awareness of constipation as a dependent variable was used to analyze factors related to awareness of constipation. For multivariate analysis, all variables were entered using forced entry. The Cochran-Armitage trend test was used to evaluate stool form by cost per month or acceptable cost per month.

\section{Results}

\section{Comparison of functional and non-functional constipation in the Japanese population}

\section{Background factors}

Of the 3,000 subjects extracted, 262 subjects ( $8.7 \%$ ) were classified into the FC group and 2,738 subjects (91.3\%) were classified into the non-FC group (Table 1). The percentage of women was significantly 
higher in the FC group than in the non-FC group (72.1\% and $47.8 \%$, respectively; $P<0.001)$. Similarly, the mean age was significantly higher in the FC group (49.8 \pm 13.1 vs. $45.8 \pm 13.3$ years; $P<0.001)$. The demographic trend showed a higher occurrence of FC in older populations, with a significantly higher frequency in individuals aged 60 and older than in other age groups (Figure 1A). The non-FC group had a significantly higher body mass index (BMI) than the FC group $\left(21.7 \pm 3.6 \mathrm{vs} .21 .0 \pm 3.3 \mathrm{~kg} / \mathrm{m}^{2}\right.$, respectively; $P=0.02)$; however, the $\mathrm{BMI}$ in both groups was lower than the national average.

A higher proportion of subjects in the non-FC group than in the FC group answered that they were either office workers $(46.2 \%$ vs. $39.3 \%$, respectively; $P=0.030)$ or retired/unemployed $(16.0 \%$ vs. $11.1 \% ; P=$ 0.030 ), whereas there were significantly more homemakers in the FC group than in the non-FC group (27.5\% vs. $14.4 \%$, respectively; $P<0.001)$. Finally, the non-FC group had higher proportions of individuals with a history of type 2 diabetes mellitus (7.2\% vs. 1.1\%; $P<0.001)$, hypertension $(13.8 \%$ vs. $9.5 \%$; $P=$ $0.060)$, anemia (17.1\% vs. $13.7 \% ; P=0.190)$, and hyperlipidemia $(11.4 \%$ vs. $9.5 \% ; P=0.410)$, as well as past treatment history of hypertension with hypertensive drugs $(10.1 \%$ vs. $5.3 \% ; P=0.010)$ and cardiovascular disease (3.0\% vs. $0.4 \% ; P=0.010)$. However, significant differences were only noted in the history of type 2 diabetes mellitus and in the past treatment history of hypertension with hypertensive drugs and cardiovascular disease.

\section{Lifestyle}

The JHPI lifestyle survey revealed that the occurrence of a past weight gain $\geq 10 \mathrm{~kg}$ was significantly more frequent in the non-FC group than in the FC group (23.0\% vs. $17.2 \% ; P=0.036)$. No association was found between FC and drinking, smoking, eating, walking, or exercising. A strong awareness of constipation was a significant factor for not having FC (Table 1).

\section{Quality of life}

The evaluation of the QOL of participants using the SF-8 questionnaire ${ }^{15}$ revealed that subjects in the FC group had a significantly higher mental component summary (MCS) than those in the non-FC group (46.7 \pm 8.3 vs. $44.4 \pm 9.2$, respectively; $P<0.001$ ), which included vitality (VT, feeling exhausted), social functioning (SF, having problems with family or friends), role emotional (RE, having difficulty in work or daily activity for psychological reasons), and mental health ( $\mathrm{MH}$, being nervous or depressed) (Table 1).

\section{Clinical symptoms}

A comparison of the two groups based on the Rome III criteria revealed that the following conditions occurred significantly more frequently in subjects in the FC group than in the non-FC group: straining, hard stool, sensation of incomplete evacuation, sensation of anorectal obstruction, rare bowel movements without the use of laxatives, and manual maneuvers to facilitate support of the pelvic floor at least $25 \%$ of defecation (Table 1 ). Loose stools that are rarely present without the use of laxatives is a 
Rome III criterion for FC, and all FC subjects (100\%) affirmed this symptom compared with only $30.8 \%$ of non-FC subjects $(P<0.001)$. Although there was no significant difference between the groups in the use of manual maneuvers (6.9\% vs. $5.3 \%$ in the FC and non-FC groups, respectively; $P=0.254$ ), very few used manual maneuvers to facilitate defecation. A significantly lower percentage of subjects with FC had stool corresponding to Bristol stool scale type 4 (i.e. normal stool) compared with those without FC $(12.2 \%$ vs. $26 \%$, respectively; $P<0.001$ ) (Figure 2 ).

\section{Source of laxative and acceptable cost}

A significantly higher proportion of FC subjects used laxatives compared with non-FC subjects ( $53.4 \%$ vs. $28.7 \% ; P<0.001)$. While no significant difference was found between the groups on the laxative purchase by a physician's prescription, laxative purchase in pharmacies, and laxative purchase online, these were more common in the FC group (Figure 3). There was significantly more variation among FC subjects in terms of the amount they were willing to pay for laxatives $(P<0.001)$, and they paid a significantly higher amount than non-FC subjects $(P<0.001)$ (Figure 4$)$.

\section{Significant background factors}

Factors found to be significant for the FC group in the univariate analysis were subjected to multivariate logistic regression analysis using a detection rate of $\leq 0.2 \%$. Age, sex, and some clinical symptoms based on Rome III criteria, including sensation of incomplete evacuation for at least $25 \%$ of defecation, sensation of hard evacuation, and manual maneuvers to facilitate support of the pelvic floor at least $25 \%$ of defecation, were found to be significant background factors related to FC. Factors found to be significant for the non-FC were onset associated with a change in frequency of stool and Bristol stool type 4. (Table 2).

\section{Comparison between strong and weak awareness of constipation}

\section{Background factors}

The survey participants $(n=3,000)$ were also classified into either strong awareness or weak awareness of constipation. A strong awareness was significantly more prevalent in women than in men $(57.3 \%$ vs. 42.7\%; $P<0.001$ ) (Table 3). A stronger awareness of constipation was observed among men in their 40s (Figure 1B). The average BMI was significantly higher in the weak awareness group; however, the subjects in both groups had a mean BMI lower than the national average in Japan.

A higher proportion of subjects in the weak awareness group answered that they were retired or unemployed than in the strong awareness group $(17.0 \%$ vs. $14.0 \% ; P=0.030)$, whereas there were 
significantly more homemakers in the strong awareness group $(17.5 \%$ vs. $13.9 \% ; P=0.006)$. Additionally, the strong awareness group had a significantly higher level of education, with a bachelor's degree or over (52.3\% vs. $39.7 \% ; P=0.020)$.

A past medical history of anemia ( $19.3 \%$ vs. $14.7 \% ; P<0.001)$ and cardiovascular disease $(3.5 \%$ vs. $2.1 \%$; $P=0.030$ ) were significantly more frequent in the strong awareness group than in the weak awareness group, whereas a history of hypertension $(14.7 \%$ vs. $11.8 \% ; P=0.020)$ was more frequent in subjects with weak awareness of constipation (Table 3).

\section{Lifestyle}

The evaluation of lifestyle using the JHPI survey showed that subjects with weak awareness of constipation "exercise aerobically for $\geq 30$ minutes twice a week for at least 1 year" and "walk faster than other people of the same age" more frequently than subjects with strong awareness of constipation. Subjects with strong awareness of constipation have "dinner within $2 \mathrm{~h}$ before going to sleep $\geq 3$ times a week", a "snack after dinner $\geq 3$ times a week", "skip breakfast $\geq 3$ times a week," and do not "get enough sleep" significantly more frequently, implying that subjects with an unhealthy lifestyle had a strong awareness of constipation.

\section{Quality of life}

The evaluation of the QOL of participants using the SF-8 questionnaire revealed that subjects with a weak awareness of constipation had a significantly higher MCS $(45.1 \pm 8.7$, vs. $44.0 \pm 9.7 ; P<0.001)$ and physical component summary (PCS) than those with a strong awareness of constipation (Table 3 ).

\section{Clinical symptoms}

A comparison of the two groups based on the Rome III criteria revealed that the following conditions occurred significantly more frequently in subjects with strong awareness of constipation: straining, hard stool, sensation of incomplete evacuation, anorectal obstruction, manual maneuvering to facilitate evacuation, and rare bowel movements without the use of laxatives (Table 3).

Subjects with a strong awareness of constipation had a significantly higher percentage of stools corresponding to Bristol stool scale types 6 and 7, whereas those with a weak awareness had types 4 (normal stool) and 5 (Figure 2).

\section{Significant background factors}

Significant factors for strong awareness in the univariate analysis were subjected to multivariate logistic regression analysis using a detection rate of $\leq 0.2 \%$. The female sex, sensation of incomplete evacuation 
for at least $25 \%$ of defecations, sensation of hard evacuation, and loose stools rarely present without the use of laxatives were found to be significant background factors related to a strong awareness of constipation. On the other hand onset associated with a change in frequency of stool, Bristol stool type 4 were associated with weak awareness of constipation. (Table 4).

\section{Discussion}

The characteristic features of FC were evaluated based on the responses of subjects extracted according to the Japanese population composition ratio, excluding those with organic diseases and those using antidepressants or other medications for the treatment of thyroid diseases, diabetes mellitus, or hypertension, which can induce secondary constipation. A study on the long-term prognosis of constipation based on population composition ratio, excluding patients with cancer and comorbidities, showed that constipation is associated with a high mortality rate. ${ }^{6}$ However, the prognosis and the prognostic factors for FC have not been elucidated. In the present study, FC was found predominantly in women, individuals with a low BMI, and the elderly (aged 60-69 years). While all members of the FC group reported difficulty in having bowel movements without laxatives, $30 \%$ of the subjects in the non-FC group also reported this symptom. Among the lifestyle factors, the only significant difference between groups was the past weight gain of $\geq 10 \mathrm{~kg}$ in the non-FC subjects; thus, no association between lifestyle and FC was detected. Interestingly, a strong awareness of constipation was considered a significant risk factor for FC (Table 1). The healthy lifestyle habits of exercising $>30$ min twice a week and walking faster than other people of the same age were significantly less common in subjects with strong awareness of constipation than in those with weak awareness. Additionally, the unhealthy habits of having late dinners (i.e. $2 \mathrm{~h}$ before sleep), getting snacks after dinner at least three times a week, skipping breakfast at least three times a week, and getting insufficient sleep were significantly more common in subjects with strong awareness. On the other hand, evaluation of QOL using the SF-8 ${ }^{15}$ revealed that subjects with non-FC had significantly lower scores for the vitality, social functioning, role emotional, and mental health subscales, whereas subjects with FC had significantly higher MCS. Irritable bowel syndrome (IBS-C) is known to have a strong negative impact on psychological status, ${ }^{16,17}$ and the results of this study confirmed that FC is associated with a lower psychological impact than IBS-C. It was also noted that a significantly higher percentage of subjects with FC were female and homemakers, and there were more office workers, retirees, and unemployed subjects in the non-FC group. Constipation is known to be prevalent in women of reproductive age. ${ }^{18}$ Anatomically, Japanese women are said to have longer colons. ${ }^{19}$ Nevertheless, a comparison of the colorectal length between American and Japanese men and women over 50 years of age revealed that there was no significant difference in colorectal length between men and women and between Japanese and American individuals. Therefore, constipation in females or in specific ethnic groups cannot be associated with a greater colorectal length. ${ }^{20}$ In the present study, the male to female ratio of subjects in their 60 s was equal in the $\mathrm{FC}$ and non-FC groups (data not shown), which suggests an association between FC and women of reproductive age. 
As for the purchase of laxatives, a significantly higher percentage of subjects with FC used laxatives, purchased either in pharmacies and online, and considered $\geq 1000$ to $\geq 5000$ yen as an acceptable cost per month for the treatment of FC without a prescription. Widely available OTC laxatives often cause significant irritation of the gastrointestinal tract, ${ }^{21}$ and appropriate medical advice from a physician is still recommended for symptom relief in both IBS-C and FC. Some researchers have suggested placing IBS-C and FC within the same disease spectrum, and while the relationship between gut microbiota and IBS-C has been investigated, ${ }^{21}$ further studies need to be conducted to determine whether the same relationship exists between $\mathrm{FC}$ and gut microbiota. ${ }^{16}$ The prevalence of chronic constipation according to the Rome III criteria is reported to be $5.5 \%$ in an online survey conducted in the USA and $2.1 \%$ based on medical consultations in Japan. ${ }^{13,16}$ According to the 2017 Comprehensive Survey of Living Conditions in Japan, ${ }^{22}$ constipation is more prevalent in women than in men. However, at the age of $>70$ years, the number of men with constipation increases, and at the age of $\geq 80$ years, the occurrences in men and women are approximately equal.

Awareness of constipation seems to stem from the subjective experience of its symptoms as well as from objective indices, such as stool frequency and consistency, which are noted by a physician.

Symptoms such as straining, sensation of incomplete evacuation, and sensation of anorectal obstruction are included in the Rome IV criteria ${ }^{1}$ and Clinical Guidelines for Chronic Constipation. ${ }^{4}$ Therefore, it is important that the physician takes these symptoms fully into account during a clinical consultation. There may also be a dysuria-type constipation, suggesting an imbalance in the defecation muscles or rectal pooling. A detailed evaluation of the chief complaint through careful history-taking may lead to a correct diagnosis of constipation.

Those who have a strong awareness of constipation more often complained of incomplete defecation and hard stools ( $n=1119,82.2 \%$ ). The infrequent reports of normal stools indicate a higher prevalence of incomplete bowel movements. Perhaps due to this, subjects feel that a good bowel movement is rare without the aid of laxatives; thus, laxative use increases. This study shows that weak constipation awareness and good lifestyle are related, as shown in people who have good health habits (i.e. walk faster than people of the same age, do not eat midnight snacks, do not skip breakfast, and have sufficient sleep) and who are less likely to have constipation are consequently less aware of the condition. The fact that the number of people who are weakly aware of constipation involving defecation being rare without laxative use was significantly lower proved that lifestyle-related habits relieve the symptoms of constipation (Table 4). This item of loose stools being rare without laxatives must be met, secondary constipation must be eliminated, and only 262 of 3000 patients were diagnosed with FC. However, 55.3\% to $82.2 \%$ of participants answering questions about the Rome III criteria (other than the two manual questions) answered that these items were applicable, demonstrating their usefulness for diagnosing chronic constipation (Table 3).

The present survey was performed over the Internet, where the risk of impersonation cannot be eliminated completely. However, we believe in the reliability of the respondents, who were registered panelists and 
whose identities can be confirmed by the survey company. The population surveyed consists of 3,000 subjects who were randomly extracted according to the population composition ratio by prefecture, sex, and age, thus reflecting the demographic profile in Japan. Nonetheless, since the upper age limit was set at 70 years in consideration of internet use among the elderly, further studies need to be conducted for the generalization of these results on Japanese subjects aged 70 years and over. Despite the aforementioned limitations, internet surveys are highly useful in performing cross-sectional studies on the actual status of certain conditions or issues due to the advantage of obtaining answers directly from participants, without any intervention or bias from healthcare personnel. Moreover, there is a shorter data collection period for a larger population size that is reflective of the population composition ratio.

\section{Conclusion}

The prevalence of FC as a form of chronic constipation is low in subjects representative of the Japanese population. It occurs often in thin subjects and in women, and in those with a strong awareness of the condition. The QOL is only slightly reduced; thus, patients with FC do not typically regard their constipation symptoms as serious health concerns. Patients with FC tend to have an irregular lifestyle, purchase laxatives in pharmacies, and are willing to pay a higher amount for OTC remedies, which shows a predisposition to treat their condition on their own. Based on an understanding of these characteristic features of FC, appropriate treatment should be provided while primarily considering the patient's symptoms and lifestyle. Patients should be well-informed about their condition and the corresponding plan of intervention to ensure that appropriate management of constipation is made widely available.

\section{Abbreviations}

functional constipation (FC)

irritable bowel syndrome (IBS)

over-the-counter (OTC)

quality of life (QOL)

Japanese Health Practice Index (JHPI)

Short Form-8 questionnaire (SF-8 questionnaire)

general health $(\mathrm{GH})$

physical functioning (PF)

role functioning (RF)

bodily pain (BP) 
vitality (VT)

social functioning (SF)

mental health $(\mathrm{MH})$

role emotional $(\mathrm{RE})$

physical component summary (PCS)

mental component summary (MCS)

body mass index (BMI)

\section{Declarations}

Ethics approval and consent to participate: This study was approved by the Institutional Review Board of Aichi Medical University (approval number: 2016-M025; Approved 2016.10.6) and was carried out in compliance with the principles of the Declaration of Helsinki and the Ethical Guidelines for Medical and Health Research Involving Human Subjects enacted by the Japanese Ministry of Education, Culture, Sports, Science and Technology and the Ministry of Health, Labour and Welfare (December 22, 2014). The internet survey and statistical analysis of the data were outsourced to Rakuten Insight, Inc. (Osaka, Japan). Participants were free to withdraw their consent at any time via the Internet.

Consent for publication: Not applicable.

Availability of data and materials: The datasets used and/or analysed during the current study are available from the institutional review board (if permitted and on reasonable request) to use in a legitimate manner.

Competing interests: The authors declare that they have no competing interests.

Funding: This study was funded by EA Pharma Co., Ltd; however, the company was not involved in the design and conduct of the study, analysis of the data, or publication of this article.

Authors' contributions:SY, YY, JU, and AK performed the research; TS, YT, SI, ME, and WO collected and analyzed the data; $\mathrm{ME}, \mathrm{KH}, \mathrm{Jl}$, and $\mathrm{YW}$ designed the research study and wrote the paper; SY, YF, NO, MS, $\mathrm{MM}$, and KK contributed to the design of the study. ALL authors approved the final version of the article, including the authorship list.

Acknowledgements: We wish to thank Rakuten Insight, Inc., for conducting the internet survey and statistical analysis of the data. Editorial support, in the form of medical writing, assembling tables and creating high-resolution images based on authors' detailed directions, collating author comments, copyediting, fact checking, and referencing, was provided by Editage, Cactus Communications, and 
funded by EA Pharma Co., Ltd. ALL authors approved the final version of the article, including the authorship list.

\section{References}

1. Drossman DA, Hasler WL. Rome IV - Functional GI disorders: disorders of gut-brain interaction. Gastroenterology. 2016;150:1257-61.

2. O'Donnell LJ, Virjee J, Heaton KW. Detection of pseudodiarrhoea by simple clinical assessment of intestinal transit rate. BMJ. 1990;300:439-40.

3. Longstreth GF, Thompson WG, Chey WD, et al. Functional bowel disorders. Gastroenterology. 2006;130:1480-91.

4. The Japanese Society of Gastroenterology. Evidence-based clinical practice guidelines for chronic constipation 2017 (ed. Research Society for the Diagnostic and Treatment of Chronic Constipation/Affiliated to The Japan Society of Gastroenterology). Nankodo; 2017.

5. Camilleri M, Ford AC, Mawe GM, et al. Chronic constipation. Nat Rev Dis Primers. 2017;3:17095.

6. Chang JY, Locke GR 3rd, McNally MA, et al. Impact of functional gastrointestinal disorders on survival in the community. Am J Gastroenterol. 2010;105:822-32.

7. Kasugai K, Yamamoto S, Kawamura Y, et al. Internet survey of the actual situation of constipation in Japanese general population REACTION-J:Research for Actual Situation of Constipation in the Japanese. Nihon Shokakibyo Gakkai Zasshi. 2019;116:913-26.

8. Kawamura Y, Yamamoto S, Funaki Y, et al. Internet survey on the actual situation of constipation in the Japanese population under 70 years old: focus on functional constipation and constipationpredominant irritable bowel syndrome. J Gastroenterol. 2020;55:27-38.

9. Albu A, Farcas A, David L, Dumitrascu DL. The economic burden of constipation therapy. Med Pharm Rep. 2019;92:261-4.

10. Miwa $H$, Toshihiro $H$, Shin'ichiro $H$. Recognizing the gap between physicians and patients suffering chronic constipation over symptoms and treatment satisfaction in Japan. Ther Res. 2017;38:110110.

11. Rao SS, Rattanakovit K, Patcharatrakul T. Diagnosis and management of chronic constipation in adults. Nat Rev Gastroenterol Hepatol. 2016;13:295-305.

12. Bharucha $A E$, Lacy BE. Mechanisms, evaluation, and management of chronic constipation. Gastroenterology. 2020;158:1232-49.e3.

13. Otani $\mathrm{K}$, Watanabe $\mathrm{T}$, Takahashi $\mathrm{K}$, et al. Prevalence and risk factors of functional constipation in the Rome IV criteria during a medical check-up in Japan. J Gastroenterol Hepatol. 2021. https://doi.org/10.1111/jgh.15436.

14. Drossman DA, Dumitrascu DL. Rome III. New standard for functional gastrointestinal disorders. J Gastrointestin Liver Dis. 2006;15:237-41. 
15. Tokuda Y, Okubo T, Ohde S, et al. Assessing items on the SF-8 Japanese version for health-related quality of life: a psychometric analysis based on the nominal categories model of item response theory. Value Health. 2009;12:568-73.

16. Ford AC, Lacy BE, Talley NJ. Irritable bowel syndrome. N Engl J Med. 2017;376:2566-78.

17. Balboa A, Mearin F, Badía X, et al. Impact of upper digestive symptoms in patients with irritable bowel syndrome. Eur J Gastroenterol Hepatol. 2006;18:1271-7.

18. Baron TH, Ramirez B, Richter JE. Gastrointestinal motility disorders during pregnancy. Ann Intern Med. 1993;118:366-75.

19. Yamazaki S, Yamazaki K, Miyazaki T, et al. An analysis on the length of the large intestine and its internal diameter amongst the Japanese. Nippon Daicho Komonbyo Gakkai Zasshi. 1994;47:31-9.

20. Nagata $\mathrm{K}$, Tajiri $\mathrm{H}$, Mitsushima $\mathrm{Y}$, et al. Colorectal length in Japanese and American asymptomatic adults based on CT colonography. Gastroenterol Endosc. 2013;55:435-44.

21. Fukudo S. Irritable bowel syndrome, emotion regulation, and gut microbiota. Brain Nerve. 2016;68:607-15.

22. Ministry of Health, Labour and Welfare. 2017 basic survey on national life https://www.mhlw.go.jp/toukei/saikin/hw/k-tyosa/k-tyosa17/index.html. Accessed July 14, 2021.

\section{Tables}

Table 1. Univariate analysis of characteristics of subjects in the functional constipation (FC) and non-FC groups, expressed in frequency or mean \pm standard deviation (SD). 
Items

FC $(\mathrm{n}=\quad$ Non-FC $(\mathrm{n}=\quad P$ value*

262) 2,738)

Residential area: North (Tohoku,

33/128/101 298/1,483/959 0.250

Hokkaido)/East (Kanto, Tokai,

Koshinetsu)/West (Kinki, Chugoku, Shikoku,

Kyushu), n/n/n

Age, years (mean \pm SD)

$49.8 \pm 13.1 \quad 45.8 \pm 13.3<0.001^{* *}$

Sex, female, $\mathrm{n}(\%)$

189 (72.1) 1,308 (47.8) <0.001**

BMI, $\mathrm{kg} / \mathrm{m}^{2}$ (mean $\pm \mathrm{SD}$ )

$21.0 \pm 3.3 \quad 21.7 \pm 3.6$

$0.002 * *$

Jobs and education

\begin{tabular}{|c|c|c|c|c|}
\hline \multirow[t]{6}{*}{$\begin{array}{l}\text { Employment status, } \\
\text { n (\%) }\end{array}$} & Student & $\begin{array}{l}10 \\
(3.8 \%)\end{array}$ & $34(1.2 \%)$ & 0.360 \\
\hline & Office worker & $\begin{array}{l}103 \\
(39.3 \%)\end{array}$ & $\begin{array}{l}1,266 \\
(46.2 \%)\end{array}$ & $0.030 * *$ \\
\hline & Self-employed & $\begin{array}{l}21 \\
(8.0 \%)\end{array}$ & $216(7.9 \%)$ & 0.900 \\
\hline & Part-time worker & $\begin{array}{l}36 \\
(13.7 \%)\end{array}$ & $389(14.2 \%)$ & 0.930 \\
\hline & Retired or unemployed & $\begin{array}{l}29 \\
(11.1 \%)\end{array}$ & $439(16.0 \%)$ & $0.030 * *$ \\
\hline & Homemaker & $\begin{array}{l}72 \\
(27.5 \%)\end{array}$ & $394(14.4 \%)$ & $<0.001^{* *}$ \\
\hline \multirow[t]{2}{*}{ Education, n (\%) } & $\begin{array}{l}\text { Junior high school or high } \\
\text { school }\end{array}$ & $\begin{array}{l}129 \\
(49.2 \%)\end{array}$ & $\begin{array}{l}1,218 \\
(44.5 \%)\end{array}$ & 0.150 \\
\hline & $\begin{array}{l}\text { Bachelor's degree or } \\
\text { higher }\end{array}$ & $\begin{array}{l}132 \\
(50.4 \%)\end{array}$ & $\begin{array}{l}1,506 \\
(55.0 \%)\end{array}$ & 0.150 \\
\hline \multicolumn{5}{|l|}{ Past history of disease } \\
\hline \multicolumn{2}{|l|}{ Hypertension, n (\%) } & $\begin{array}{l}25 \\
(9.5 \%)\end{array}$ & $377(13.8 \%)$ & 0.060 \\
\hline
\end{tabular}


Type 2 diabetes mellitus, $\mathrm{n}(\%)$

$\begin{array}{lll}3(1.1 \%) & 196(7.2 \%) & <0.001^{* *} \\ 25 & 313(11.4 \%) & 0.410\end{array}$

Hyperlipidaemia, n (\%)

$(9.5 \%)$

Lesion in the stomach, duodenum or small

0

$291(10.6 \%) \quad$ NA

intestine, $\mathrm{n}(\%)$

Inflammatory bowel disease, $\mathrm{n}(\%)$

0

0

Hemorrhoids, n (\%)

0

$395(14.4 \%) \quad$ NA

Diverticulum, n (\%)

0

Gastrointestinal cancer, n (\%)

0

Cerebrovascular disease, n (\%)

0

Chronic obstructive pulmonary disease, n (\%)

0

$35(1.3 \%)$

NA

Liver disease, $\mathrm{n}(\%)$

0

Kidney disease, $\mathrm{n}(\%)$

0

Abdominal surgery without appendectomy, $n$

0

0

(\%)

Anemia, n (\%)

36

$468(17.1 \%)$

0.190

$(13.7 \%)$

Past treatment history

Hypertensive drugs, n (\%)

14

$60(2.2 \%)$

NA

$5(0.2 \%)$

NA

$62(2.3 \%)$

NA

$62(2.3 \%)$

NA

0

(5.3\%)

Insulin injections or hyperglycemia drugs, $\mathrm{n}(\%) \quad 0$

Hyperlipidemia drugs, n (\%)

22

$123(4.5 \%)$

NA

$264(9.6 \%)$

0.580

$(8.4 \%)$

Cerebrovascular disease, $\mathrm{n}(\%)$

0

$80(2.9 \%)$

NA

Cardiovascular disease, $\mathrm{n}(\%)$

$1(0.4 \%)$

$81(3.0 \%)$

$0.010^{* *}$

Chronic renal failure or history of dialysis, $\mathrm{n}$

0

$26(0.9 \%)$

NA

(\%)

Depression or anxiety, n (\%)

0

$314(11.5 \%)$

NA

Lifestyle factors based on JHPI questionnaire 
Smoking more than 100 cigarettes per month

and smoking for 6 month or longer, n (\%)

Alcohol drinking occasionally or daily, n (\%)

Walking for $1 \mathrm{~h} / \mathrm{d}, \mathrm{n}(\%)$

Body weight gain of at least $10 \mathrm{~kg}, \mathrm{n}(\%)$

Exercising for more than 30 minutes twice a week for at least 1 year, n (\%)

Walking or similar exercise for more than $1 \mathrm{~h} / \mathrm{d}, \quad 56$

n (\%)

Walking faster than other people of the same age, $\mathrm{n}(\%)$

Body weight gain or loss of at least $3 \mathrm{~kg}$ within 186

year, n (\%)

Eating faster than other people, n (\%)

Having dinner within $2 \mathrm{~h}$ before going to sleep at 67

least 3 times a week, n (\%)

Eating snacks after dinner at least 3 times a

week, n (\%)

Skipping breakfast at least 3 times a week, $\mathrm{n}$ (\%)

Insufficient sleep, $\mathrm{n}(\%)$

Strong awareness of constipation, n (\%)
$(37.0 \%)$

$(32.8 \%)$

100

$(38.2 \%)$

$39(1.4 \%)$

0.580

(15.6\%)

156

1,046

0.900

$(59.5 \%)$

$(38.2 \%)$

100

1,027

0.730

(38.2\%)

(37.5\%)

45

$630(23.0 \%)$

$0.036^{* *}$

(17.2\%)

57

564 (20.6\%)

0.630

(21.8\%)

97

1,038

0.790

$567(20.7 \%) \quad 0.610$

(37.9\%)

$928(33.9 \%)$

0.780

$(37.5 \%)$

$794(29.0 \%) \quad 0.290$

83

797 (29.1\%)

0.390

(31.7\%)

69

$715(26.1 \%)$

0.940

(26.3\%)

144

1,588

0.350

(55.0\%)

(58.0\%)

71

1,171

$<0.001 * *$

(27.1\%)

Rome III criteria question items 
Improvement with defecation, $\mathrm{n}(\%)$

194

1,933

0.255

(74.0\%)

$(70.6 \%)$

Onset associated with a change in frequency of 133

1,613

$0.013^{* *}$

stool, n (\%)

$(50.8 \%)$

$(58.9 \%)$

Onset associated with a change in form

137

1,577

0.103

(appearance) of stool, n (\%)

$(52.3 \%)$

$(57.6 \%)$

Straining during at least $25 \%$ of defecation, $n$

211

1,828

$<0.001 * *$

(\%)

$(80.5 \%)$

$(66.8 \%)$

Lumpy or hard stool at least $25 \%$ of defecations, 210

1,682

$<0.001^{* *}$

n (\%)

$(80.2 \%)$

$(61.4 \%)$

Sensation of incomplete evacuation for at least $\quad 230$

1,828

$<0.001 * *$

$25 \%$ of defecation, $\mathrm{n}(\%)$

$(87.8 \%)$

$(66.8 \%)$

Sensation of hard evacuation, n (\%)

255

2,036

$<0.001^{* *}$

$(97.3 \%)$

$(74.4 \%)$

Manual maneuvers to facilitate digital

18

$144(5.3 \%)$

0.254

evacuation at least $25 \%$ of defecation, $\mathrm{n}(\%)$

$(6.9 \%)$

Manual maneuvers to facilitate support of the

62

$321(11.7 \%)$

$<0.001 * *$

pelvic floor at least $25 \%$ of defecation, n (\%)

$(23.7 \%)$

Loose stools are rarely present without the use $\quad 262$

$843(30.8 \%) \quad<0.001^{* *}$

of laxatives, n (\%)

$(100.0 \%)$

Quality of life (SF-8)

\begin{tabular}{lllc}
\hline $\mathrm{GH}^{\dagger}($ mean $\pm \mathrm{SD})$ & $46.9 \pm$ & $46.1 \pm 7.8$ & 0.121 \\
& 7.5 & & \\
$\mathrm{PF}^{\ddagger}($ mean $\pm \mathrm{SD})$ & $47.2 \pm$ & $46.9 \pm 9.0$ & 0.532 \\
& 9.5 & & \\
\hline $\mathrm{RP}^{\S}($ mean $\pm \mathrm{SD})$ & $48.6 \pm$ & $47.9 \pm 7.9$ & 0.158 \\
& 7.1 & & \\
\hline $\mathrm{BP}^{\top}($ mean $\pm \mathrm{SD})$ & $48.5 \pm$ & $48.3 \pm 8.6$ & 0.655 \\
& 8.3 & &
\end{tabular}




\begin{tabular}{|c|c|c|c|}
\hline $\mathrm{VT}^{\dagger \dagger}($ mean $\pm \mathrm{SD})$ & $\begin{array}{l}48.1 \pm \\
7.4\end{array}$ & $46.5 \pm 7.9$ & $0.002^{* *}$ \\
\hline $\mathrm{SF}^{\ddagger \ddagger}($ mean $\pm \mathrm{SD})$ & $\begin{array}{l}47.9 \pm \\
9.1\end{array}$ & $45.9 \pm 10.2$ & $0.002^{* *}$ \\
\hline $\mathrm{MH}^{\S \S}($ mean $\pm \mathrm{SD})$ & $\begin{array}{l}48.9 \pm \\
7.7\end{array}$ & $47.2 \pm 8.3$ & $0.001^{* *}$ \\
\hline $\mathrm{RE}^{\boldsymbol{\top} \boldsymbol{\top}(\text { mean } \pm \mathrm{SD})}$ & $\begin{array}{l}45.0 \pm \\
10.5\end{array}$ & $43.1 \pm 10.9$ & $0.010^{* *}$ \\
\hline PCS $^{\dagger+\dagger}$ (mean \pm SD) & $\begin{array}{l}46.9 \pm \\
7.1\end{array}$ & $46.9 \pm 7.5$ & 0.966 \\
\hline $\mathrm{MCS}^{\ddagger \neq \neq}($ mean $\pm \mathrm{SD})$ & $\begin{array}{l}46.7 \pm \\
8.3\end{array}$ & $44.4 \pm 9.2$ & $<0.001^{* *}$ \\
\hline
\end{tabular}

*The level of significance is set at $P<0.05$.

**Significant difference between groups.

${ }^{\dagger} \mathrm{GH}$, general health; ${ }^{\ddagger} \mathrm{PF}$, physical functioning; ${ }^{\S} \mathrm{RP}$, role physical; ${ }^{\circledR} \mathrm{BP}$, body pain; ${ }^{\dagger} \mathrm{VT}$,

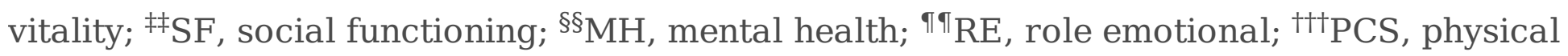
component summary; ${ }^{\ddagger \neq \ddagger} \mathrm{MCS}$, mental component summary.

Table 2. Multivariate analysis of background factors significant for functional constipation (FC). 


\begin{tabular}{|c|c|c|c|c|c|c|c|c|}
\hline & Odds & $95 \% \mathrm{C}$ & & $P$ value* & Odds & $95 \% \mathrm{C}$ & & $P$ value* \\
\hline Age & 1.023 & 1.013 & 1.033 & $<0.001 * *$ & 1.032 & 1.020 & 1.045 & $<0.001 * *$ \\
\hline Sex $($ female $=1)$ & 0.353 & 0.267 & 0.468 & $<0.001 * *$ & 0.380 & 0.260 & 0.498 & $<0.001^{* *}$ \\
\hline BMI & 0.942 & 0.906 & 0.980 & $0.003^{* *}$ & & & & \\
\hline
\end{tabular}

Jobs and

education

$\begin{array}{lllll}\text { Office worker } & 0.753 & 0.581 & 0.976 & 0.032^{* *}\end{array}$

$\begin{array}{lllll}\text { Retired or } & 0.677 & 0.449 & 1.023 & 0.064\end{array}$

unemployed

\begin{tabular}{lllll} 
Homemaker & 2.255 & 1.685 & 3.018 & $<0.001^{* *}$ \\
\hline Bachelor's degree & 0.634 & 0.485 & 0.827 & $<0.001^{* *}$
\end{tabular}

or higher

Past history of

disease

\begin{tabular}{lcccccccc}
\hline Hypertension & 0.629 & 0.414 & 0.956 & $0.030^{* *}$ & & & & \\
\hline $\begin{array}{l}\text { Type 2 diabetes } \\
\text { mellitus }\end{array}$ & 0.150 & 0.048 & 0.473 & $0.001^{* *}$ & 0.191 & 0.058 & 0.627 & $0.006^{* *}$ \\
\hline Dyslipidaemia & 0.689 & 0.459 & 1.034 & 0.072 & & & & \\
\hline Anaemia & 0.213 & 0.149 & 0.305 & $<0.001^{* *}$ & 0.173 & 0.119 & 0.252 & $<0.001^{* *}$ \\
\hline $\begin{array}{l}\text { Rome III criteria } \\
\text { question items }\end{array}$ & & & & & & & & \\
\hline
\end{tabular}

Improvement with $\quad 1.188 \quad 0.891 \quad 1.585 \quad 0.241$

defecation

$\begin{array}{lllllllll}\text { Onset associated } & 0.719 & 0.558 & 0.927 & 0.011^{* *} & 0.689 & 0.477 & 0.996 & 0.048^{* *}\end{array}$

with a change in

frequency of stool

Onset associated $\quad 0.807 \quad 0.626 \quad 1.040 \quad 0.098$

with a change in 
form or

appearance of

stool

Straining during $\quad 2.060 \quad 1.502 \quad 2.825 \quad<0.001^{* *}$

at least $25 \%$ of

defecation

Lumpy or hard $\quad 2.535 \quad 1.854 \quad 3.468<0.001^{* *}$

stool at least $25 \%$

of defecations

$\begin{array}{lllllllll}\text { Sensation of } & 3.578 & 2.451 & 5.223 & <0.001^{* *} & 1.953 & 1.283 & 2.974 & 0.002^{* *}\end{array}$

incomplete

evacuation for at

least $25 \%$ of

defecation

Sensation of hard $12.56 \quad 5.899 \quad 26.744<0.001^{* *} \quad 8.152 \quad 3.600 \quad 1.846<0.001^{* *}$

evacuation

Manual

$\begin{array}{llll}1.329 & 0.801 & 2.208 & 0.271\end{array}$

maneuvers to

facilitate digital

evacuation at

least $25 \%$ of

defecation

Manual

2.334

1.716

3.176

$<0.001^{* *}$

1.587

1.123

2.241

$0.009 * *$

maneuvers to

facilitate support

of the pelvic floor

at least $25 \%$ of

defecation

Loose stools are

rarely present 
without the use of

laxatives

$\begin{array}{lllllllll}\text { Bristol stool type } & 0.395 & 0.270 & 0.578 & <0.001^{* *} & 0.585 & 0.386 & 0.888 & 0.012^{* *}\end{array}$ 4

Source of laxative

$\begin{array}{lllll}\text { History of laxative } & 5.851 & 4.341 & 7.886 & <0.001 * *\end{array}$

use

$\begin{array}{lllll}\text { Pharmacy } & 2.684 & 2.056 & 3.505<0.001 * *\end{array}$

Internet $\quad 2.103 \quad 1.446 \quad 3.015<0.001^{* *}$

Acceptable

laxative cost

More than $1000 \quad 1.806 \quad 1.384 \quad 2.357 \quad<0.001 * *$

yen

$*$ The level of significance is set at $P<0.05$.

**Significant difference between groups.

Table 3. Univariate analysis of characteristics of subjects with strong or weak awareness of constipation, expressed in frequency or mean \pm standard deviation (SD). 


\begin{tabular}{|c|c|c|c|c|}
\hline \multicolumn{2}{|l|}{ Items } & $\begin{array}{l}\text { Strong } \\
\text { awareness of } \\
\text { constipation } \\
(n=1,362)\end{array}$ & $\begin{array}{l}\text { Weak } \\
\text { awareness of } \\
\text { constipation } \\
(n=1,638)\end{array}$ & $P$ value* \\
\hline $\begin{array}{l}\text { Residential } \\
\text { area }\end{array}$ & $\begin{array}{l}\text { North (Tohoku, Hokkaido)/East } \\
\text { (Kanto, Tokai, Koshinetsu)/West } \\
\text { (Kinki, Chugoku, Shikoku, } \\
\text { Kyushu), n/n/n }\end{array}$ & $136 / 736 / 490$ & $193 / 875 / 570$ & 0.280 \\
\hline Age & Years, $($ mean $\pm \mathrm{SD})$ & $46.3 \pm 12.9$ & $46.0 \pm 13.8$ & 0.500 \\
\hline Sex & Female, (\%) & 57.3 & 48.8 & $<0.001^{* *}$ \\
\hline BMI & $\mathrm{kg} / \mathrm{m}^{2}($ mean $\pm \mathrm{SD})$ & $21.4 \pm 3.6$ & $21.8 \pm 3.5$ & $0.001 * *$ \\
\hline \multicolumn{2}{|c|}{ Jobs and education } & $\mathrm{n}$ & $\mathrm{n}$ & \\
\hline \multirow[t]{6}{*}{ Jobs, n (\%) } & Student & $15(1.1 \%)$ & $20(1.2 \%)$ & 0.850 \\
\hline & Office worker & $619(45.4 \%)$ & $750(45.8 \%)$ & 0.870 \\
\hline & Self-employed & $108(7.9 \%)$ & $129(7.9 \%)$ & $>0.999$ \\
\hline & Part-time worker & $191(14.0 \%)$ & $234(14.3 \%)$ & 0.870 \\
\hline & Retired or unemployed & $190(14.0 \%)$ & $278(17.0 \%)$ & $0.030 * *$ \\
\hline & Homemaker & $239(17.5 \%)$ & $227(13.9 \%)$ & $0.006 * *$ \\
\hline \multirow{2}{*}{$\begin{array}{l}\text { Education, } \\
\mathrm{n}(\%)\end{array}$} & Junior high school, High school & $647(47.5 \%)$ & $715(43.7 \%)$ & $0.010 * *$ \\
\hline & Bachelor's degree or over & $712(52.3 \%)$ & $650(39.7 \%)$ & $0.020 * *$ \\
\hline \multicolumn{2}{|c|}{ Past history of disease } & $\mathrm{n}$ & $\mathrm{n}$ & \\
\hline \multicolumn{2}{|c|}{ Hypertension, n (\%) } & $161(11.8 \%)$ & $241(14.7 \%)$ & $0.020 * *$ \\
\hline \multicolumn{2}{|c|}{ Type 2 diabetes mellitus, n (\%) } & $90(6.6 \%)$ & $95(5.8 \%)$ & 0.360 \\
\hline \multicolumn{2}{|c|}{ Hyperlipidemia, n (\%) } & $153(11.2 \%)$ & $185(11.3 \%)$ & $>0.999$ \\
\hline \multicolumn{2}{|c|}{$\begin{array}{l}\text { Lesion in the stomach, duodenum or small } \\
\text { intestine, } \mathrm{n}(\%)\end{array}$} & $131(9.6 \%)$ & $160(9.8 \%)$ & 0.900 \\
\hline \multicolumn{2}{|c|}{ Inflammatory bowel disease, n (\%) } & 0 & 0 & \\
\hline \multicolumn{2}{|c|}{ Hemorrhoids, n (\%) } & $161(11.8 \%)$ & $234(14.3 \%)$ & 0.051 \\
\hline \multicolumn{2}{|c|}{ Diverticulum, n (\%) } & $11(0.8 \%)$ & $24(1.5 \%)$ & 0.120 \\
\hline
\end{tabular}


Gastrointestinal cancer, n (\%)

Cerebrovascular disease, n (\%)

Chronic obstructive pulmonary disease, n (\%) 1 (0.1\%)

Liver disease, $\mathrm{n}(\%)$

Kidney disease, n (\%)

Abdominal surgery without appendectomy, $\mathrm{n} \quad 0$

(\%)

Anemia, n (\%)

$27(2.0 \%)$

$31(2.3 \%)$

0

$263(19.3 \%)$

$241(14.7 \%)$

$<0.001 * *$

Past treatment history

Hypertensive drugs, n (\%)

$123(9.0 \%)$

$167(10.2 \%)$

0.290

Insulin injections or hyperglycemia drugs, $\mathrm{n}$

$59(4.3 \%)$

$64(3.9 \%)$

0.580

(\%)

Hyperlipidemia drugs, n (\%)

Cerebrovascular disease, n (\%)

Cardiovascular disease, $\mathrm{n}(\%)$

Chronic renal failure or history of dialysis, $\mathrm{n} \quad 12$ (0.9\%) (\%)

Depression or anxiety, n (\%)

$157(11.5 \%)$

$157(9.6 \%)$

0.090

Lifestyle factors based on JHPI questionnaire

Smoking more than 100 sticks per month, $\mathrm{n} \quad 197$ (14.5\%) $236(14.4 \%) \quad 0.920$ (\%)

Alcohol consumption, n (\%)

$804(59.0 \%)$

$998(60.9 \%)$

0.310

Body weight increased by $10 \mathrm{~kg}$ or more

$315(23.1 \%)$

$359(21.9 \%)$

0.430

from the age of $20, \mathrm{n}(\%)$

Exercising for more than 30 minutes twice a 259 (19.0\%)

$360(22.0 \%)$

$0.040 * *$

week for at least 1 year

Walking for $1 \mathrm{~h} / \mathrm{d}, \mathrm{n}(\%)$

$520(38.2 \%)$

$614(37.5 \%)$

0.730

Walking faster than other people of the same

$463(34.0 \%)$

$621(37.9 \%)$

$0.030 * *$ age, n (\%) 
Eating faster than other people, n (\%)

Having dinner within $2 \mathrm{~h}$ before going to

sleep at least 3 times a week, n (\%)

Eating snacks after dinner at least 3 times a week, n (\%)

Skipping breakfast at least 3 times a week, $\mathrm{n}$ (\%)

Insufficient sleep, $\mathrm{n}(\%)$

$821(60.3 \%)$

909 (55.5\%)

$0.010^{* *}$

Rome III criteria question items

Improvement with defecation, $\mathrm{n}(\%)$

$964(70.8 \%)$

$1,163(71.0 \%)$

0.904

Onset associated with a change in frequency

$789(57.9 \%)$

$957(58.4 \%)$

0.795

of stool, n (\%)

Onset associated with a change in form or

$753(55.3 \%)$

$961(58.7 \%)$

0.064 appearance of stool, n (\%)

Straining during at least 25\% of defecation, n 989 (72.6\%)

$1,050(64.1 \%) \quad<0.001 * *$ (\%)

Lumpy or hard stool at least $25 \%$ of $933(68.5 \%)$

$959(58.5 \%)$ $<0.001 * *$ defecations, n (\%)

Sensation of incomplete evacuation for at

$1,040(76.4 \%)$

$1,018(62.1 \%) \quad<0.001^{* *}$

least $25 \%$ of defecation, $n(\%)$

Sensation of hardly any evacuation, n (\%)

Manual maneuvers to facilitate digital

$1,119(82.2 \%)$

$1,172(71.6 \%) \quad<0.001 * *$

evacuation at least $25 \%$ of defecation, n (\%)

Manual maneuvers to facilitate support of the

$95(7.0 \%)$

$67(4.1 \%)$

$0.001 * *$

pelvic floor at least $25 \%$ of defecation, n (\%)

Loose stools are rarely present without the

$753(55.3 \%)$

$352(21.5 \%)$ $<0.001^{* *}$ use of laxatives, n (\%)

Quality of life (SF-8)

$\mathrm{GH}^{\dagger}($ mean $\pm \mathrm{SD})$

$45.5 \pm 8.1$

$46.8 \pm 7.4$

$<0.001^{* *}$ 


\begin{tabular}{|c|c|c|c|}
\hline $\mathrm{PF}^{\ddagger}($ mean $\pm \mathrm{SD})$ & $46.2 \pm 9.8$ & $47.5 \pm 8.3$ & $<0.001^{* *}$ \\
\hline $\mathrm{RP}^{\S}($ mean $\pm \mathrm{SD})$ & $47.6 \pm 8.2$ & $48.3 \pm 7.6$ & $0.003^{* *}$ \\
\hline $\mathrm{BP}^{\top}($ mean $\pm \mathrm{SD})$ & $47.9 \pm 8.9$ & $48.5 \pm 8.3$ & $0.041^{* *}$ \\
\hline $\mathrm{VT}^{\dagger \dagger}($ mean $\pm \mathrm{SD})$ & $46.0 \pm 8.2$ & $47.2 \pm 7.5$ & $<0.001^{* *}$ \\
\hline $\mathrm{SF}^{\ddagger \ddagger}($ mean $\pm \mathrm{SD})$ & $45.4 \pm 10.8$ & $46.6 \pm 9.4$ & $<0.001 * *$ \\
\hline $\mathrm{MH}^{\S \S}($ mean $\pm \mathrm{SD})$ & $46.6 \pm 8.8$ & $48.0 \pm 7.7$ & $<0.001 * *$ \\
\hline $\mathrm{RE}^{\boldsymbol{\top} \boldsymbol{\top}}($ mean $\pm \mathrm{SD})$ & $43.0 \pm 11.1$ & $43.5 \pm 10.6$ & 0.169 \\
\hline $\mathrm{PCS}^{\dagger+\dagger}($ mean $\pm \mathrm{SD})$ & $46.5 \pm 7.8$ & $47.3 \pm 7.1$ & $0.003^{* *}$ \\
\hline $\mathrm{MCS}^{\ddagger \neq \ddagger}($ mean $\pm \mathrm{SD})$ & $44.0 \pm 9.7$ & $45.1 \pm 8.7$ & $0.001^{* *}$ \\
\hline
\end{tabular}

*The level of significance is set at $P<0.05$.

**Significant difference between groups.

${ }^{\dagger} \mathrm{GH}$, general health; ${ }^{\ddagger} \mathrm{PF}$, physical functioning; ${ }^{\S} \mathrm{RP}$, role physical; ${ }^{\Uparrow} \mathrm{BP}$, body pain; ${ }^{\dagger} \mathrm{VT}$,

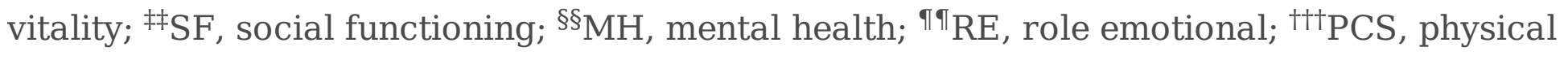
component summary; ${ }^{\ddagger \neq \ddagger} \mathrm{MCS}$, mental component summary.

Table 4. Multivariate analysis of background factors significant for strong awareness of constipation. 


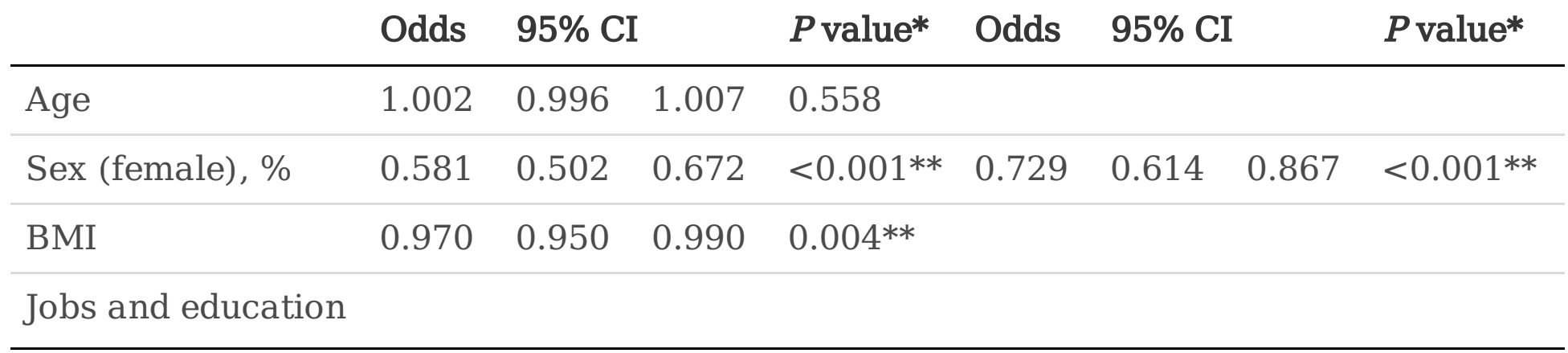

\begin{tabular}{lllll}
\hline Office worker & 0.986 & 0.854 & 1.140 & 0.853 \\
\hline
\end{tabular}

$\begin{array}{lllll}\text { Retired or } & 0.726 & 0.588 & 0.895 & 0.003^{* *}\end{array}$

unemployed

Homemaker $\quad \begin{array}{llll}1.323 & 1.085 & 1.612 & 0.006^{* *}\end{array}$

$\begin{array}{lllllllll}\text { Bachelor's degree } & 0.730 & 0.631 & 0.844 & <0.001 * * & 0.849 & 0.721 & 1.000 & 0.050^{* *}\end{array}$ or over

Past history of disease

\begin{tabular}{lllllllll}
\hline Hypertension & 0.794 & 0.646 & 0.976 & $0.029 * *$ & 0.692 & 0.545 & 0.878 & $0.003^{* *}$ \\
\hline Diabetes & 1.083 & 0.812 & 1.444 & 0.589 & & & & \\
\hline Dyslipidemia & 0.994 & 0.810 & 1.219 & 0.952 & & & & \\
\hline Anemia & 1.141 & 0.985 & 1.321 & 0.078 & & & & \\
\hline
\end{tabular}

Rome III criteria question items

\begin{tabular}{lllll}
\hline Improvement with & 0.989 & 0.845 & 1.159 & 0.894
\end{tabular} defecation

$\begin{array}{lllll}\text { Onset associated } & 0.980 & 0.847 & 1.134 & 0.784\end{array}$

with a change in frequency of stool
Onset associated
0.871
$0.753 \quad 1.007 \quad 0.062$
$0.783 \quad 0.664$
$0.9240 .004^{* *}$

with a change in

form or 
appearance of

stool

Straining during at $1.485 \quad 1.270 \quad 1.736<0.001 * *$

least $25 \%$ of

defecation

Lumpy or hard $\quad \begin{array}{llll}1.450 & 1.324 & 1.790<0.001 * *\end{array}$

stool at least $25 \%$

of defecations

$\begin{array}{llllllllll}\text { Sensation of } & 1.967 & 1.676 & 2.308 & <0.001^{* *} & 1.457 & 1.202 & 1.790 & 0.001 * *\end{array}$

incomplete

evacuation for at

least $25 \%$ of

defecation

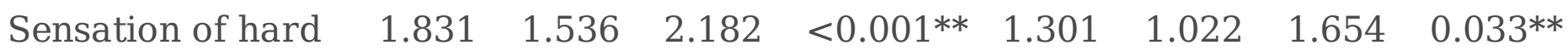

evacuation

Manual maneuvers $1.759 \quad 1.276 \quad 2.435 \quad<0.001^{* *}$

to facilitate digital

evacuation at least

$25 \%$ of defecation

Manual maneuvers $1.786 \quad 1.438 \quad 2.220<0.001^{* *}$

to facilitate

support of the

pelvic floor at

least $25 \%$ of

defecation

Loose stools are $\quad 4.516 \quad 3.852 \quad 5.295 \quad<0.001^{* *} \quad 4.070 \quad 3.439 \quad 4.817<0.001^{* *}$

rarely present

without the use of

laxatives

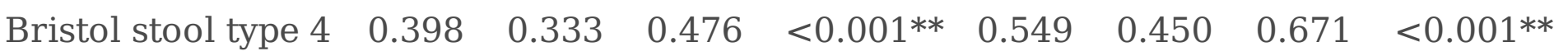


Source of laxative

History of laxative $\begin{array}{lllll}2.887 & 2.483 & 3.358 & <0.001^{* *}\end{array}$

use

\begin{tabular}{lllll} 
By prescription & 1.572 & 1.329 & 1.859 & $<0.001^{* *}$ \\
\hline Pharmacy & 1.375 & 1.189 & 1.590 & $<0.001^{* *}$ \\
\hline Internet & 1.561 & 1.210 & 2.013 & $<0.001^{* *}$
\end{tabular}

Acceptable

laxative cost

More than $1000 \quad 2.083 \quad 1.762 \quad 2.482<0.001^{* *}$

yen

*The level of significance is set at $P<0.05$.

**Significant difference between groups.

\section{Figures}

(A)

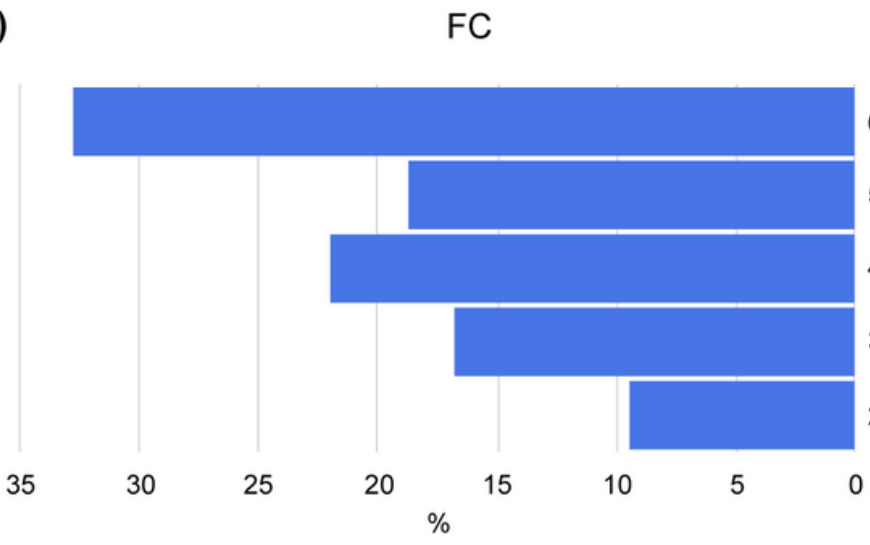

(B)

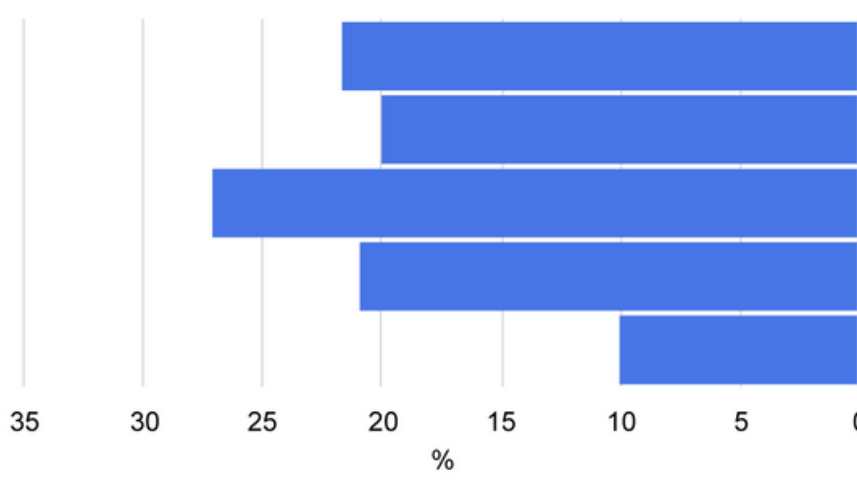

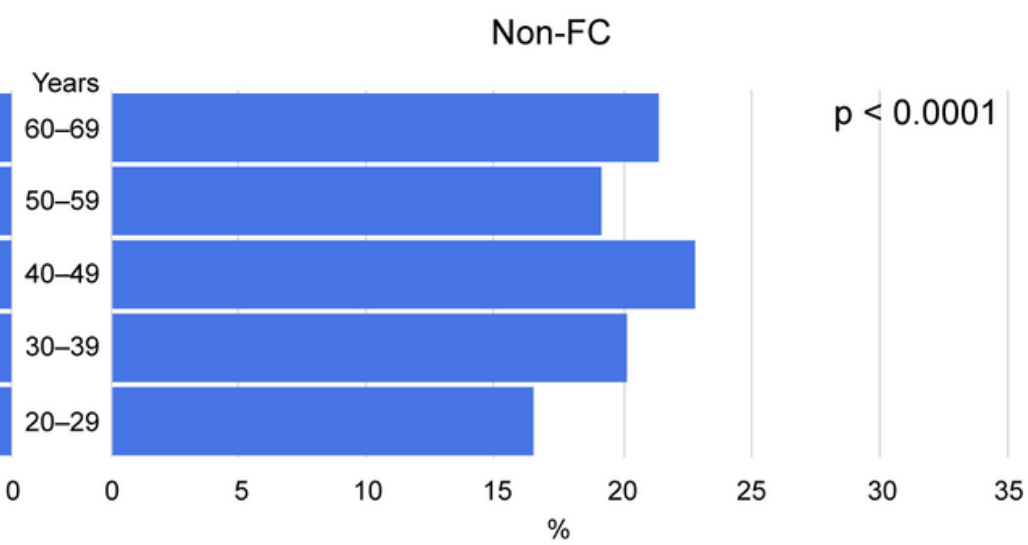

Weak awareness

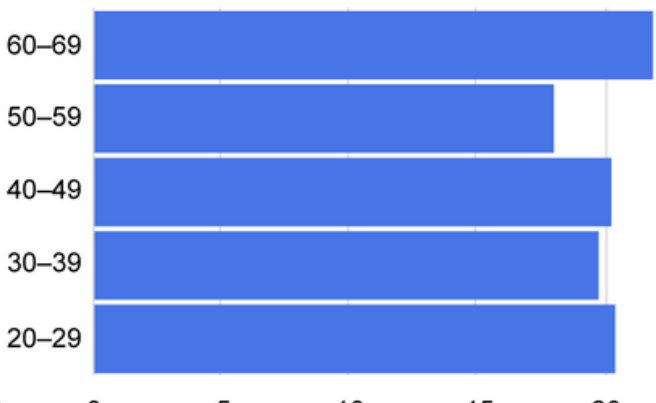

25

$p=0.293$

(1)

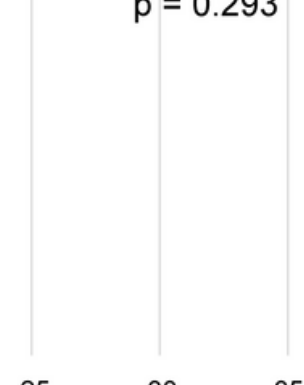

35 
Age trends. Comparison of age range between FC and non-FC (A) and between strong awareness and weak awareness of constipation (B).

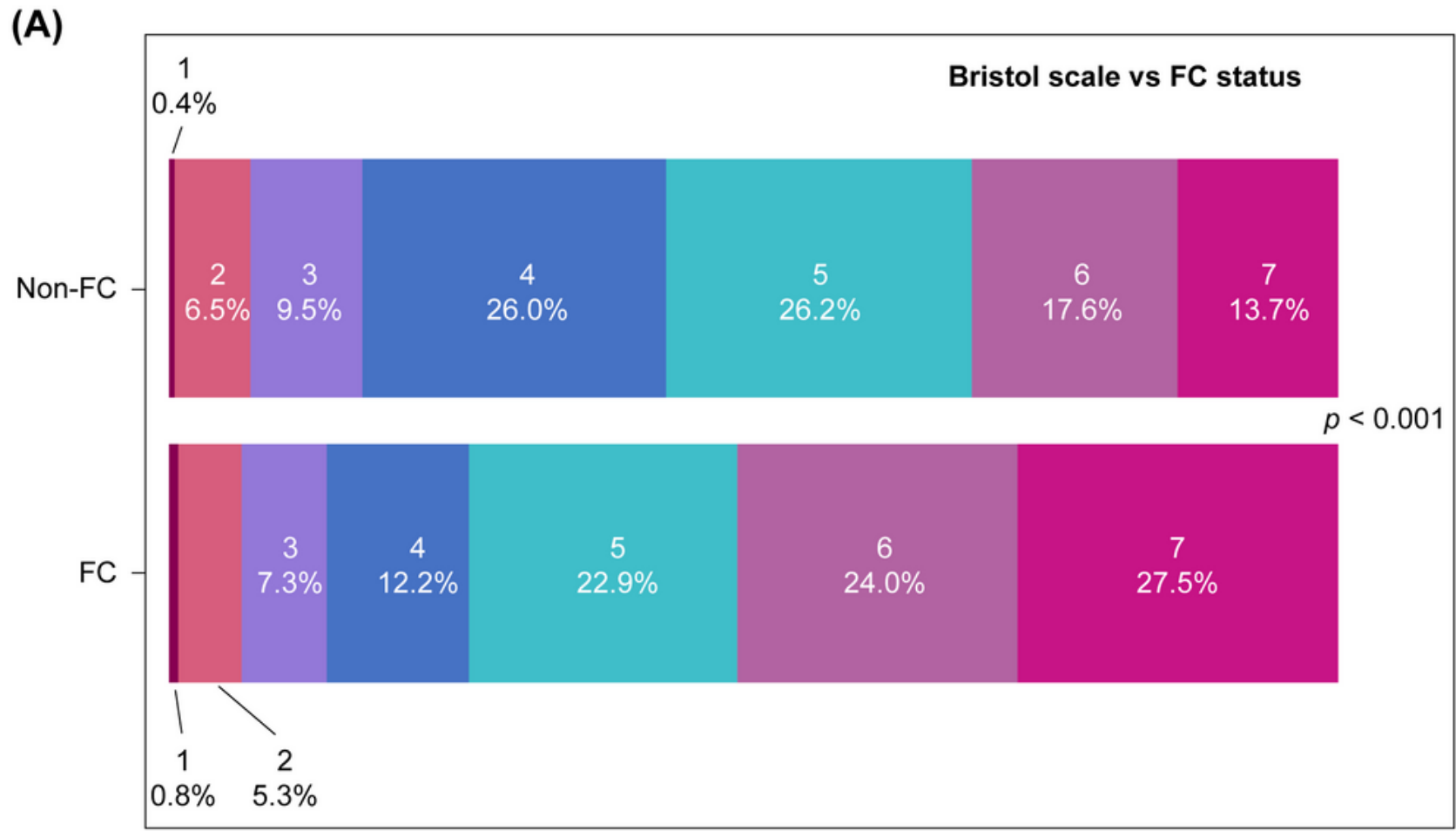

(B)

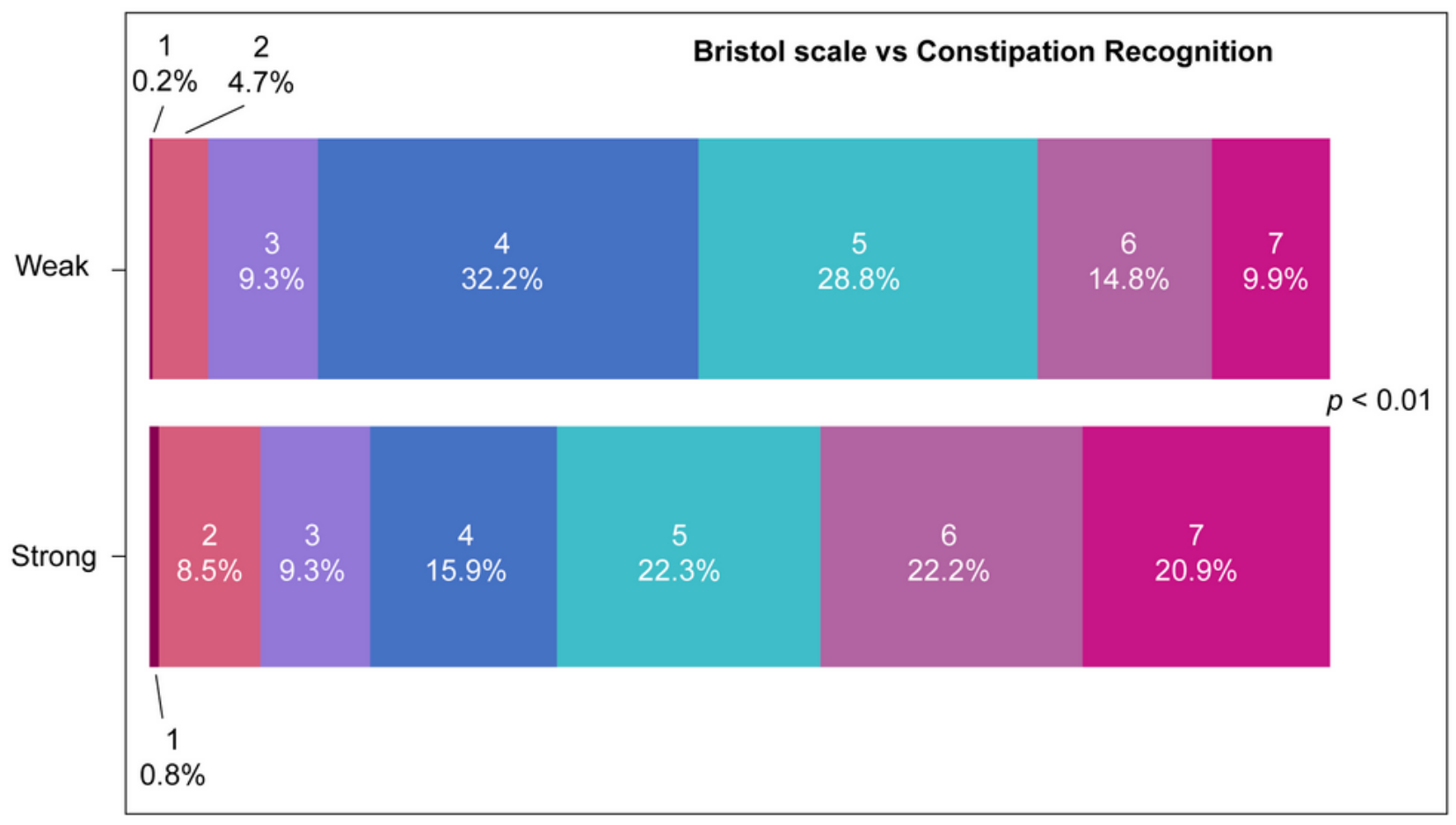

\section{Figure 2}

Bristol scale. Comparison of stool types between FC and non-FC (A) and between strong awareness and weak awareness of constipation (B). 1: Watery, no solid pieces; 2: fluffy pieces with ragged edges, a mushy stool; 3: soft blobs with clear cut, smooth and soft, passed early; 4: like sausage or snake, smooth 
and soft; 5: like sausage but with cracks on surface; 6: sausage shaped but lumpy; 7: shaped hard lumps, like nuts, hard to pass.

(A)
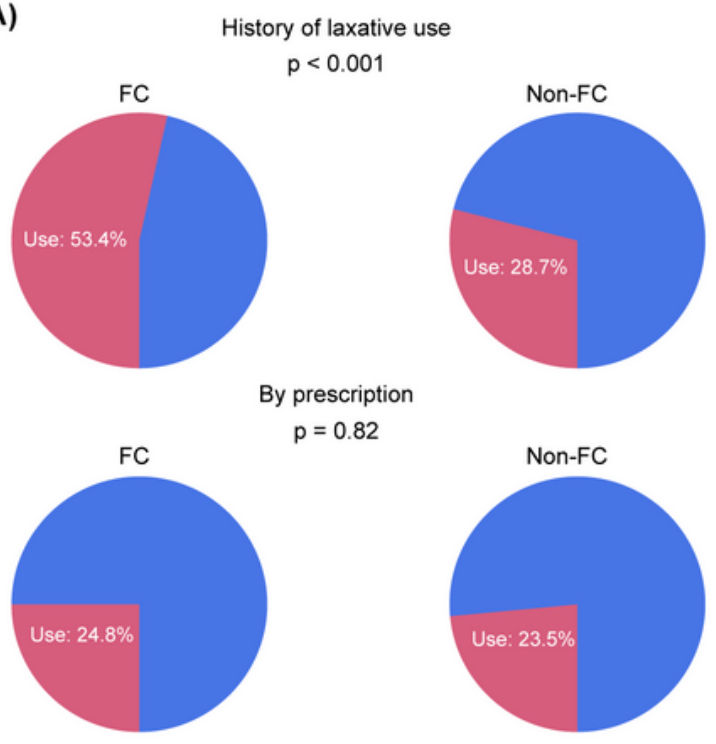

Pharmacy

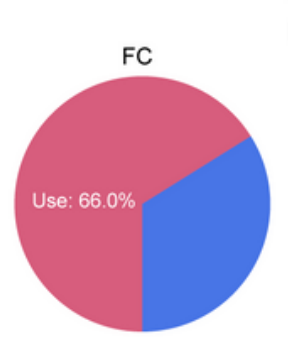

$p<0.001$
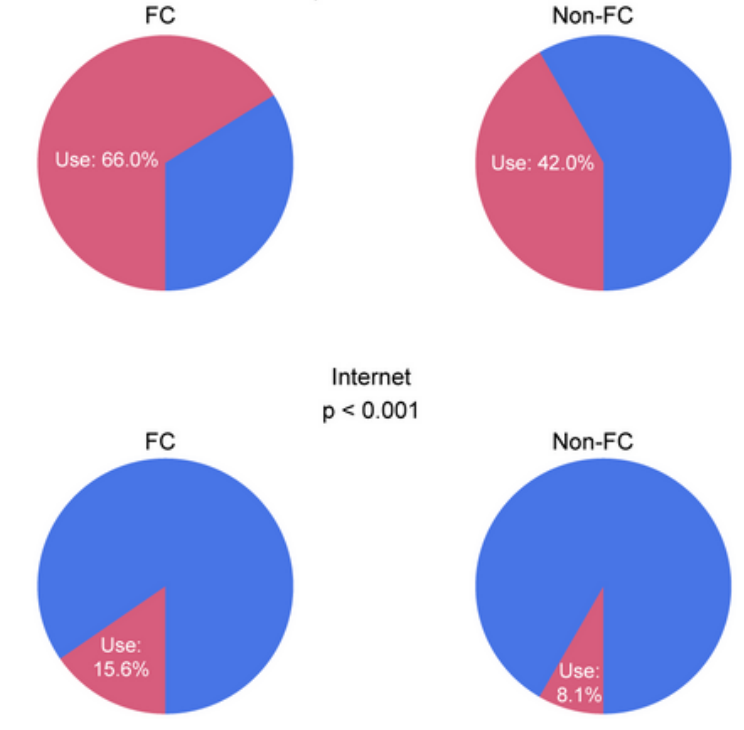

Internet $p<0.001$

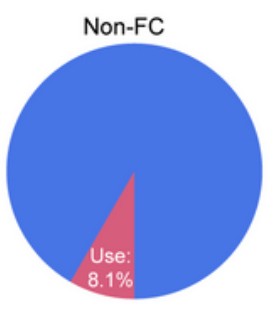

Bristol 4 stool and other $p<0.001$

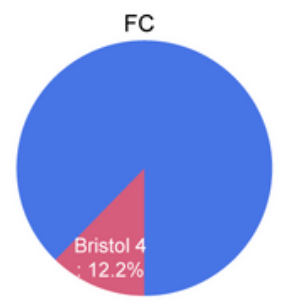

(B)

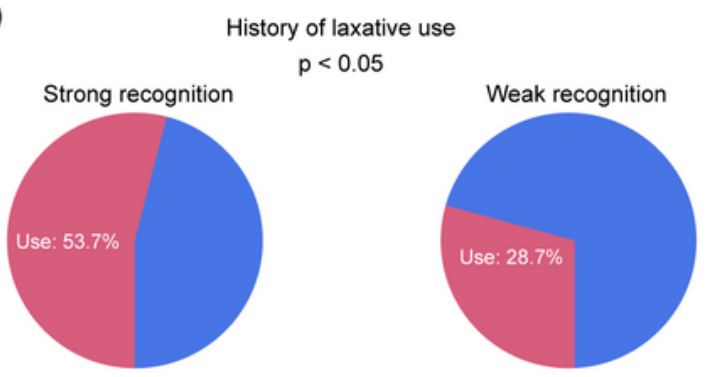

By prescription

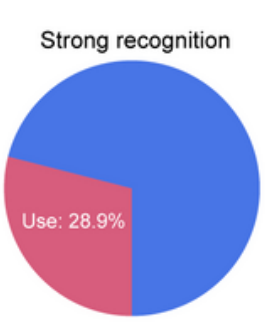

$p<0.001$

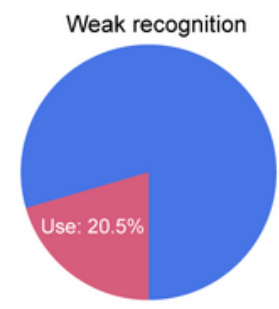

Pharmacy

$p<0.001$
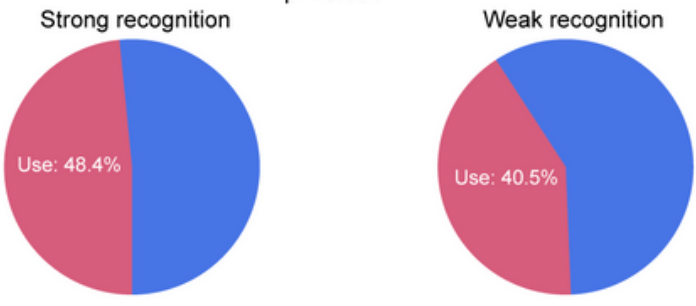

Internet

$p<0.01$
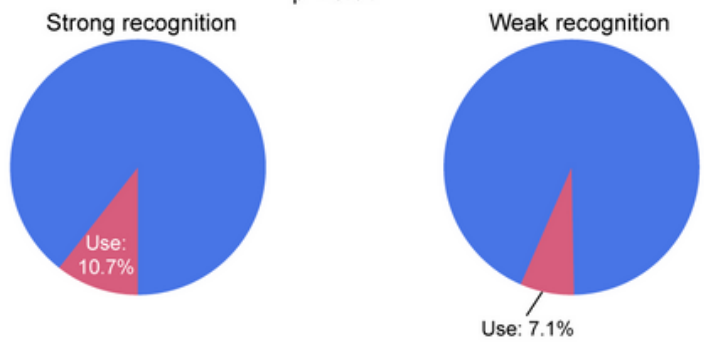

Bristol 4 stool and other $\mathrm{p}<0.001$
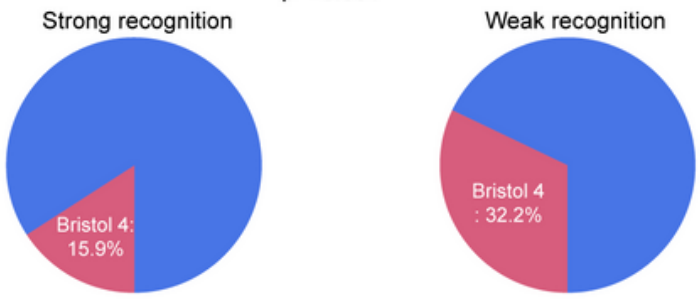

\section{Figure 3}

History of laxative use. Comparison of laxative purchase. Comparison of Bristol 4 stool scale between functional constipation (FC) and non-FC; and (A) between strong awareness and weak awareness of constipation (B). 
(A)

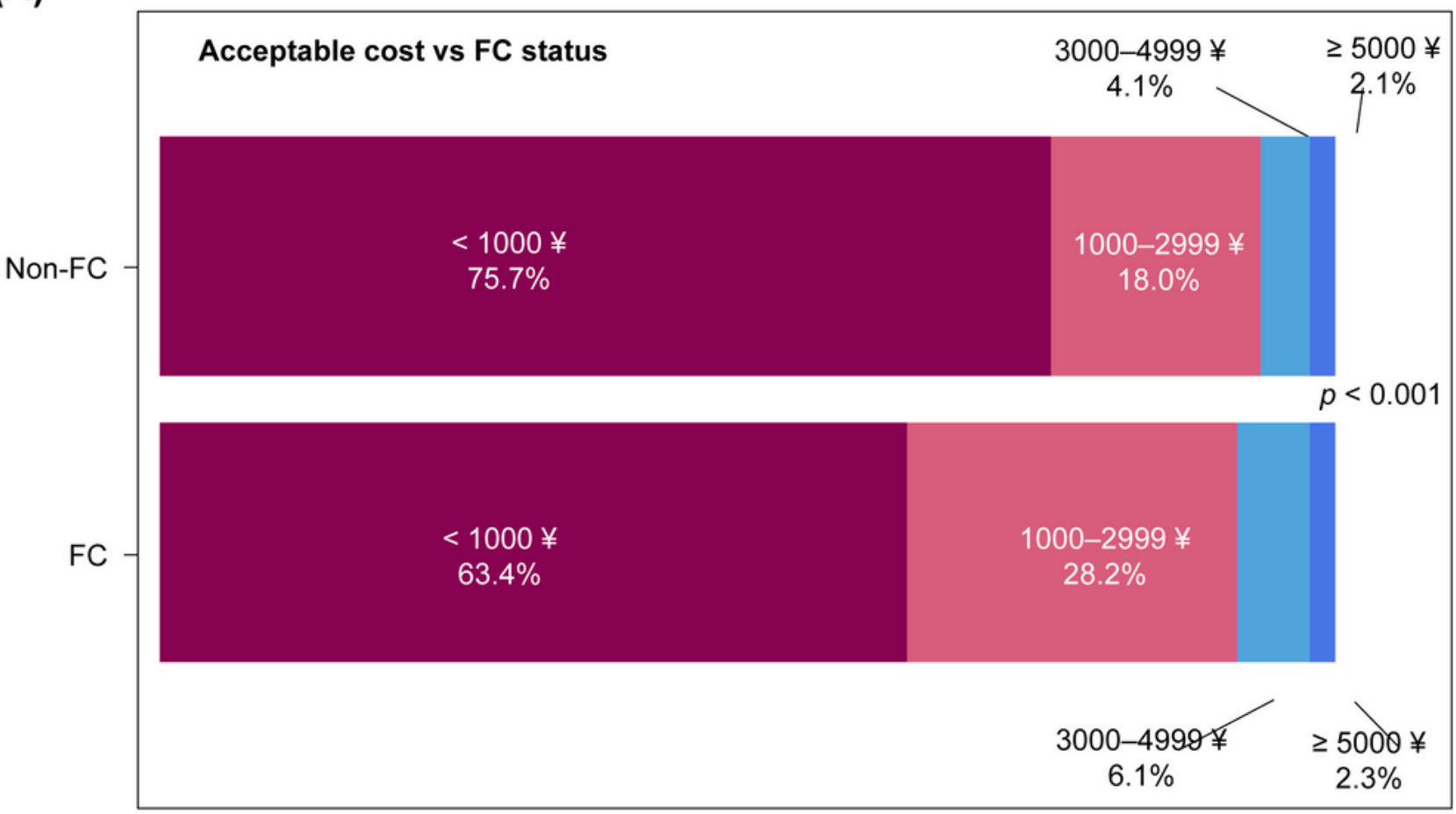

(B)

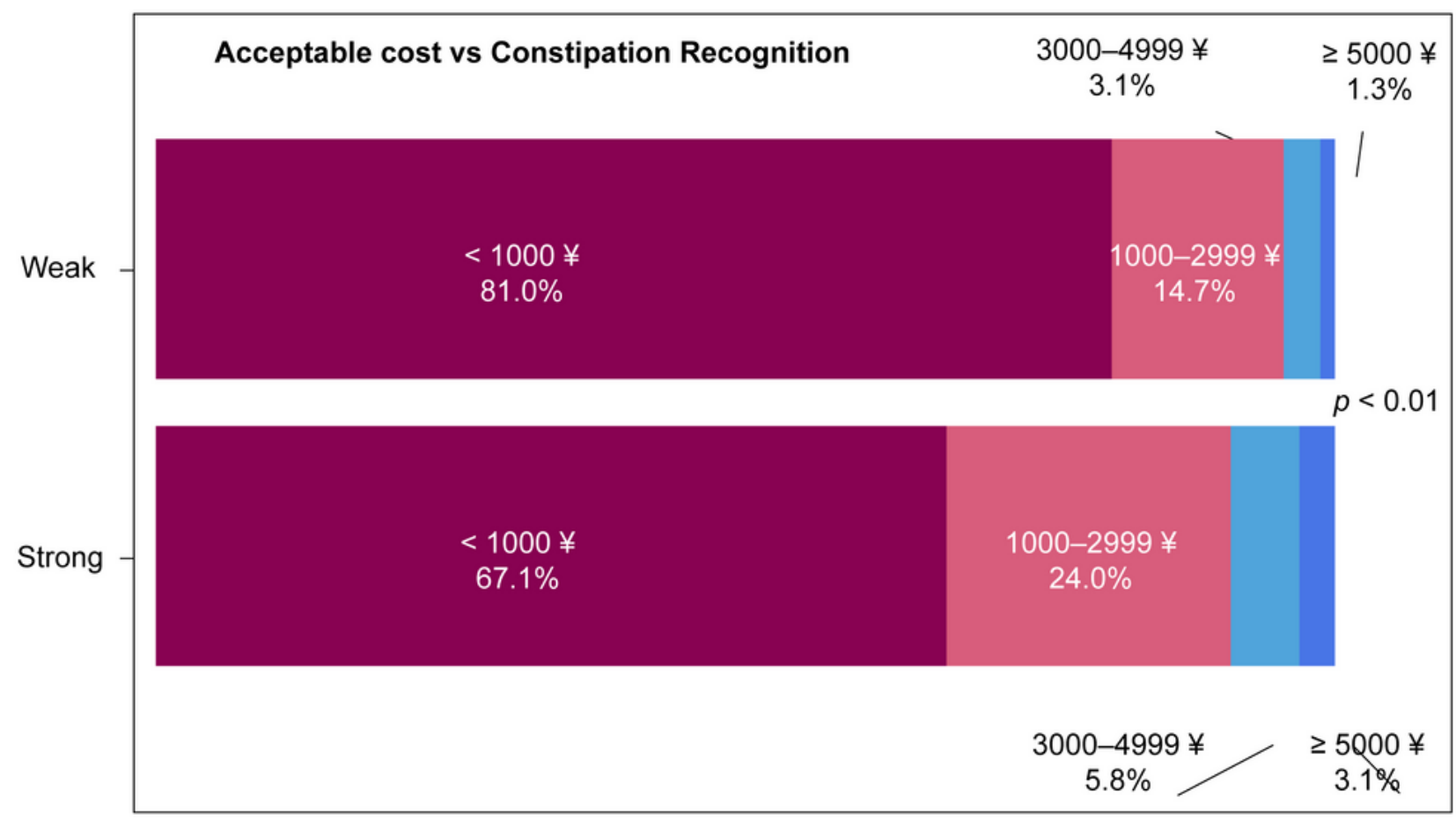

\section{Figure 4}

Acceptable cost of laxatives. Comparison of cost of laxatives between FC and non-FC (A) and between strong awareness and weak awareness of constipation (B). 